\title{
Q
}

ISSN 2278 - 0211 (Online)

\section{Investigating a Dynamic Relationship between Oil Revenue, Government Expenditure and GDP Per Capita Growth: The Nigerian Experience}

\author{
Igwe Ikechukwu \\ Ph.D. Candidate, Department Name: Petroleum Economics \\ Institution name: Emerald Energy Institute, University of Port Harcourt, Nigeria \\ Dr. Obindah Gershon \\ Senior Lecturer, Department of Economics and Development Studies, \\ Covenant University, Ota, Ogun State, Nigeria \\ Dr. Omowumi Iledare \\ Director, Emerald Energy Institute, Department of Faculty of Petroleum Engineering \\ University of Port Harcourt, Nigeria
}

\begin{abstract}
:
Within the last four decades, Nigeria economy has been struggling through a recovery process for the GDP per capita, the living standard and wellbeing of her citizens to improve. This paper examines oil revenue management and its impact on gross domestic product per capita in Nigeria from 1970 to 2015 using econometric techniques of vector autoregressive (VAR) model. The pre-estimation, tests (unit root, cointegration and lag selection criteria) informed the decision to estimate a vector error correction mechanism. The VECM estimate shows that one period lag of oil revenue had a positive but an insignificant impact on gross domestic product per capita. Furthermore, government expenditure and national savings had a negative, but an insignificant impact on gross domestic product per capita. The impulse response shows that a unit standard deviation shock to oil revenue on gross domestic product per capita will be positive from the first year till the tenth year. Whereas, government total expenditure and national savings will be negative from the first year till the tenth year. The variance decomposition shows that a shock in government total expenditure, oil revenue and gross national savings will account for an average of $2.06 \%, 0.09 \%$ and $2.05 \%$ variation respectively on gross domestic product per capita during a 10 year period. This implies that a shock in government expenditure would react more to GDP per capita growth and improvement of the welfare of Nigerians. This study concludes that oil revenue has a positive, but an insignificant impact on GDP per capita growth, however, government expenditure and national savings has negative but insignificant impact on GDP per capita growth. This suggests that an efficient management system of transmitting oil revenue to government expenditure and savings should be implemented to increase GDP per capita growth and improve wellbeing of Nigerians.
\end{abstract}

Keyword: Nigeria, oil revenue, gross domestic product per capita and vector auto regression

\section{Introduction}

\subsection{Background}

Nigeria has a lot to gain from the large crude oil reserve she is blessed with through efficient management of accrued revenue. It has the 6th largest gas reserves, 11th largest crude oil reserves, 11th in crude oil production and (EIA, 2017). The economy of Nigeria is highly dependent on oil resources; oil revenue constitutes $96 \%$ of total exports, $80 \%$ of government revenues and about 20\% of GDP (IMF, 2017). Although the agricultural sector was previously the main driver of the economy between 1960 and early 1970s while revenue from other sources was considered as surplus (CBN, 2008). Nonetheless, the oil boom experience of 1973/ 1974 altered the revenue generation structure in Nigeria. The federally collected revenue share of oil revenue rose from $26.3 \%$ in 1970 to $81.8 \%$ in 1979, 72.6\% in 1989 and $76.3 \%$ in 1999 (CBN, 2006). The oil and gas sector also contributed $77.5 \%$ of federally collected revenue from 1986 to 2012 while the non - oil sector generated only $22.5 \%$ for the same period (CBN, 2015). 
From 2005 to 2013, oil revenue was 77\%, while that of non-oil revenue was 33\% (World Bank, 2014). Oil production was $1.810 \mathrm{mbpd}$ in 1990, 1.993, in 2.165 out of 2000, 2.627 in 2005, 2.455 in 2010 and 2.316 in 2015 (World Bank, 2016). The increase in oil production and oil revenue in Nigeria, is expected to favour overall gross domestic product per capita and economic growth. However, the GDP per capita has been increasing at snail pace. Gross domestic product per capita implies a measure of a nation's economic output that accounts for its number of people. It is obtained through the division of the nation's GDP by its total population. That makes it the best measurement of a nation's standard of living, by revealing how prosperous a nation touches every one of its citizens. It measures the monetary value, the cost of goods and services produced in a nation. To allow for comparisons between nations over time, the total economic output of a nation is placed in relation to the number of citizens in that nation which is the GDP per capita.

Nigeria GDP per capita of Nigeria rose to $132 \%$ in the sixties achieving accelerated growth of $283 \%$ in the seventies. In any case, this appeared unsustainable and it therefore shrank by $66 \%$ in the eighties. However, the diversification initiatives that commenced in the nineties restored the declining growth to 10\% (CBN, 2001). In 2012, the GDP at purchasing power parity was virtually high, rising in 2000 to $\$ 170$ billion, in 2012 to $\$ 451$ billion. This was not the case with GDP purchasing power parity until the 2000's. Correspondingly, the GDP per capita grew for every individual from $\$ 1400$ in 2000 to a projected $\$ 2,800$ for every individual in 2012. There was also rise in population with a record figure of 160 million in 2010 from 120 million in 2000 (Fact fish, 2017). The GDP in 2012 was made up by the accompanying divisions: agriculture: 40\%; services: 30\%; manufacturing: 15\%; oil: 14\% (NBS, 2012). However, by 2015, government lack of interest in other sectors altered the composition of the GDP to: agriculture: 18\%; services: $55 \%$; manufacturing: 16\%; oil: $8 \%$ (NBS, 2015). Consequently, the value of GDP per capita growth (annual \%) in Nigeria was -4.16 as of 2016 (World Bank, 2017). Interestingly, 30.36\% in 2004 has been the highest record, with a declining value as low as $-17.55 \%$ in 1967 . Nigeria GDP per capita was at the level of $\$ 1,994$ in 2017, down from $\$ 2,208$ the previous year, this is a change of $9.68 \%$ (World Bank, 2017).

Creating opportunities to improve gross national product per capita in Nigeria's through oil revenue is very essential; it is the engine that drives growth and economic stability. Crude oil is an exhausting resources which aren't renewable, proceeds from oil should serve as an opportunity to generate extra wealth (Ross, 1999; Auty, 2001; Sachs and Warner, 1995). This implies that oil revenues and windfalls should be seen as a facilitator towards meeting development targets (Fernanda, 2010). Oil resources based economy like Nigeria have a chance to utilize the oil riches to support development initiatives like education, poverty reduction and infrastructure as a priority. Infrastructure will offer a base for linkages across the oil and gas sector, promoting creativity and innovation (Frankel, 2012). Education will create an environment where innovation can thrive, and will likewise provide the work force to support the industries where specialized knowledge is required.

To achieve a sustainable level of development and improve the standard of living, Nigeria has enough reason to improve her GDP per capita growth. It is on this premise that the nation needs to develop a healthy oil revenue management framework. However, various other critical supports do exist for the appropriation of this goal. The reliance on oil revenues opens the nation to the danger of fluctuating hydrocarbon prices (Askari and Jaber, 1999). The volatility in oil prices prompts significant changes in the terms of trade in oil exports. Besides reducing the economy's exposure to oil price changes, efficient management of oil revenue would encourage judicious spending and saving of oil wind fall against the period of price decline.

\subsection{Statement of the Problem}

The key factor in a vibrant economy is its capacity to grow its GBP per capita output, sufficient to improve the standard of living of its citizens if the source of income is managed sustainably. From 1974 to 2015, more than 500 billion have been generated from oil revenue in Nigeria (CIA, 2016). The nation has witnessed a growth rate of oil revenue flow with an average of $71.8 \%$ from 1970 to 1980, 29.4\% from 1981 to 1990, 46.3\% from 1991 to 2000, 21.1\% from 2001 to 2010 and 08\% from 2010 to 2015 respectively (CBN, 2016). Oil production increased on the average $8.1 \%$ from 1970 to $1980,-3.2 \%$ from 1981 to 1990, 1.8\% from 1991 to 2000, 1.5\% from 2001 to 2010 and -1.1\% from 2011 to 2015 respectively (OPEC, 2017). The total government expenditure increased on the average $23.2 \%$ from 1980 to $1989,46.03 \%$ from 1990 to 1999 , $15.3 \%$ from 2000 to 2009 and $6.9 \%$ from 2010 to 2015 while government savings also increased 19.5\% from 1980 to 1989 , $28.7 \%$ from 1990 to 1999, 36.4\% from 2000 to 2009 and $12.9 \%$ from 2010 to 2015. However, GDP per capita was \$1018 in 1974, \$2702 in 1980, \$1053 in 1986, \$1299 in 2005, \$2327 in 2010, and \$2176 in 2016 respectively.

The implication of the GDP per capita growth shows that not much have changed over a long period, an average person has been very poor. The GDP per capita growth and incomes remained almost unchanged over a period of several decades when compared to the increase in oil production, oil revenue influx, total government expenditure and savings. Average incomes as measured by GDP per capita in Nigeria between the year 1970 and 2016 were $\$ 265.61$ when measured in today's prices. With higher population growth of about $2.7 \%$ growth annually against a lower GDP growth of $1 \%$, it means that the GDP per capita is declining (CBN, 2006). Most studies have argued that oil revenue impact positively on GDP per capita (Anthony, 2012; Carbonnier and Wagner, 2012; Odularu, 2008). Some other studies believe oil revenue does not translate to GDP per capita growth (Frederick, 2006; George, Syed and Sebastian, 2011; Akanni, 2007). There is a lack of consensus on the impact of oil revenue on the GDP per capita growth in Nigeria. This reinforces the need for this paper to investigate the impact of oil revenue on the GDP per capita and well-being of Nigerians. 


\subsection{Aim and Objectives}

The aim of this study is to investigate the existence of a dynamic relationship between oil revenue, government expenditure and GDP per capita in Nigeria between. In specific terms, the study:

- Examined the impact of oil revenue on government total expenditure;

- Investigated the effect of government expenditure on GDP per capita;

- Forecasted the nature and magnitude of variation in government total expenditure explained by oil revenue; and

- Forecasted the nature and magnitude of variation in GDP per capita explained by government total expenditure.

\subsection{Hypotheses}

For the purpose of this paper, the following research hypotheses were tested:

- $\quad \mathrm{H}_{0}$ : Oil revenue has no significant impact and causality on government total expenditure.

- $\quad \mathrm{H}_{0}$ : Government total expenditure has no significant impact and causality on GDP per capita growth.

\subsection{Significance of the Study}

The significance of this paper dwells on increasing knowledge of oil revenue management for GDP per capita growth, wellbeing and living standard of Nigerians. In a wider sense, it will facilitate our understanding of the relationship between oil revenue and GDP growth. This paper is also timely in view of current government initiatives to stabilize the economy and take Nigeria to the part of economic prosperity. It will help in the formulation of national and local policies that would go a long way to address not only corruption in the management of our oil revenue and poor economic growth, but also poverty, which goes hand in hand with the GDP per capita growth and standard of living.

\section{Literature Review}

\subsection{Theoretical Review}

This paper is supported by economic growth theories: the classical, neo-classical, and new theories of growth. This theory forms the basis for most studies on economic growth. GDP is the market value of all final goods and services produced in a nation. Gross domestic product per capita is a measure of a nation's economic output that accounts for its number of people (Kimberly, 2018). That makes it the best estimation of a nation's standard of living and wellbeing. The GDP and GDP per capita of a nation is increased continuously for the economic growth trend upwards, through these economic growth theories:

\subsubsection{Classical Theory}

The classical theory: this is an economic growth term with a blend of economic theory effort initiated by Smith (1776), Ricardo (1817) and Malthus (1798) in the 80's and 90's centuries. The theory expresses that each economy, features a stable state GDP and any deviation from that stable state is short-term and will in the long run return. Essentially, this depends on the idea that population rises as GDP grow. The increase in population, hence adversely affects GDP because of the high demand on inadequate resources from a larger population. The GDP will in the end decline back to the stable state. At the point when GDP deviates below the stable state, the population will decrease and in this manner lower down demands on the resources. Thus, the GDP will ascend back to its stable state.

\subsubsection{Neoclassical Theory}

The neoclassical theory was propounded by two economists (Swan and Solow, 1956). The theory explains how capital accumulation and technological changes constitute the leading force able to enhance economic growth. It portrays some important features like economic growth, which can be achieved through the full employment of labour; the substitution of production factors; the growth rate of population increases correlation with economic rate; the dependence. According to Solow (1956) the economic growth of a nation as well as the standard of living of individuals depend on the level of saving and investment. Essentially, if the investment per capita exceeds the depreciation increase of existing capital per capita, every worker will benefit from a more advanced equipment and it should be able to produce more. Thus, by the measure of the principle of decreasing yields, the capital per capita increase leads to the production growth, but not proportional, the production will rise at a lower rate than the costs associated with, and the growth will cease over time. This explains the coming together among some countries, but also the emphasis in global inequalities between the rich and poor countries. The coming together of countries for the sake as of development, can be achieved through the efforts of investment in human and technical capital.

\subsubsection{The New Theories of Growth}

The new growth theory, developed by Romer (1987) and Lucas (1988) advocates the importance of the concept of human capital. How employees with higher knowledge, training and education can increase rates of technological innovation. They stress the need for governments to strongly boost technological advancement. They contend in the free market classical view, firms may have no inducement to participate in new technologies since they will struggle to profit in competitive 
markets. The model dwells on increasing both capital and labour efficiency. It stresses that expanding labour output does not have consistent losses, but rather, may have increasing returns. Though, increasing capital does not really prompt, consistent losses as Solow (1956) predicts. Rather, it is more complicated and depends on the type of capital investment. More attention is attached to free-markets, reducing control and supports. The contention is that we have to keep economies open to the forces of change. Schumpeter (1934) contended that an integral element of capitalism was the creative destruction, enabling ineffective firms to collapse was fundamental for enabling resources to flow into more productive channels. Grossman and Helpman (1994) asserts that the new growth theory is that we keep on increasing living standards for a considerable length of time by relentlessly enhancing our insight into how to produce better products and services with smaller amounts of physical resources.

\subsection{Empirical Review}

Few empirical works have been carried out by researchers to investigate the impact of oil revenue management on GDP per capita growth in Nigeria. This paper captures related empirical reviews with the aim of making a broader contribution to literatures on the topic. Oladipo and Fabayo (2012) utilized OLS to explore the effect of the global economic decline in the oil sector and economic growth in Nigeria. The data from 1990to 2006 were employed to determine the effect of oil production on GDP output. The results, discoveries demonstrate that there was a negative relationship between GDP and oil produced. Anthony (2012) explores the centrality of oil in the change of the Nigerian economy in a multivariate VAR model from 1960 to 2009. Outcome of the findings demonstrates that there is cointegration among the five subsectors and that the oil can cause other non-oil divisions to grow.

Chinyere (2012) carried out an empirical investigation on the impact of export trading on economic growth in Nigeria from 1987 to 2012. The Ordinary Least Squares (OLS) and Granger Causality test which was used to determine the level of impact that one variable has on the other as well as the direction of causality between them. The result indicates that oil export positively and significantly impacted on the growth of Nigeria's economy for the period under review. It was also shown in the result that non-oil export has a positive and significant impact on GDP. The result of the granger causality test indicates that there is a unidirectional causality between oil export and GDP.

Baker and Fawehinmi (2011) evaluated the econometric examination of how oil income has influenced the way of life in Nigeria. The OLS regression method was employed to examine the data from 1975 to 2008 . The outcomes demonstrated a significant and negative connection between oil revenue and standard of living in Nigeria.

$\mathrm{Li}$ and Zhou (2011) examine the total and conditional connection of real GDP per capita among 164 world economies from 1970-2006. The data driven model measurement tests prompted the utilization of nonparametric and semi-parametric models. The estimation outcomes demonstrate that control factors play a negative/ positive route impact in the growth convergence for poor/advance economies. The best convergence theory tends to hold just for the economies with low development levels, yet the restrictive convergence speculation tends to hold for every one of the economies

Afolabi (2011) examines the effect of oil export on economic growth in Nigeria utilizing RGDP as the dependent variable and labour, capital domestic consumption, oil export and aggregate generation as independent variables from 1970 2006. The results demonstrate that oil export has huge 1 "effect on economic growth in Nigeria.

Kalbasi (2010) used, settled effect models to test the assumption of convergence among Middle East countries from 1995 to 2005. Both absolute and restrictive convergence was utilized by the author for both GDP and per capita salary. Moreover, they isolated countries into two sub-groups, oil producing nations and that of non-oil producers, to see whether an association exists inside both gathering and whether the speed of convergence is remarkable. The outcomes reinforce the presence of convergence for the per capita income, however not for the GDP growth. Likewise, it was discovered that the absolute convergence is rejected for non-oil producers when we utilized GDP growth. Inference from his deduction suggest that there is a propensity of convergence among Middle East nations, the speed of convergence is diverse for oil producers compared with non-oil producers.

Chidinma (2010), using two independent models, gross national product and investment individually, looks at the relative impact of oil and non-oil exports to Nigeria economic growth from 1983 to 2007. The independent variable oil exports, non-oil trade, real exchange rate and inflation rate were modelled to capture their effect on GDP and investment respectively. It moreover used log linear model to observe that non-oil export have not contributed an impressive measure to economic growth in Nigeria. However, other indicators exact much influence on the growth of the economy.

Awe and Ajayi (2009) examine the effect of non-oil revenue on economic development. The impact of the revenue from the agricultural sector, solid mineral and the manufacturing sector on the Gross Domestic Product (GDP) was carried out. The analytical technique used was co-integration analysis, which comprises the use of unit root test and error correction model. The findings revealed that dynamic relationship exists between the revenue from the non-oil sector and economic development. The major Subsector of the non-oil sectors, agriculture, manufacturing and solid minerals tested individually on the total revenue and all have significant results except manufacturing.

\section{Research Methods}

\subsection{Methodology for the Study}


The Vector auto-regression (VAR) model was adopted as the key model for this work to identify the movement and the relationship between all the variables in the VAR model are treated symmetrically by including for each variable and equation explaining its evolution based on its own lags and the lags of all the other variables in the model. To estimate the model, some tests were carried out which included: Test for stationarity (unit root test), cointegration, VAR estimate test, Granger causality test, impulse response function test and forecast error variance decomposition test.

\subsection{Model Specification}

For the purpose of analysing and forecasting macroeconomic activities, and tracing the relationship between oil revenue and inflation rate in Nigeria economy, VAR models in addition to forecasting have been used to serve two primary functions: testing causality and studying the effects of shocks through impulse response characterization and forecast error variance decomposition. This study, therefore, estimated a vector autoregressive (VAR) model to trace the effect of crude oil revenue fluctuation on inflation growth in Nigeria. We specified the generalized VAR model as:

$\mathrm{Y}=\Pi_{0}+\Pi_{1} \mathrm{X} 1+\Pi_{2} \mathrm{X} 2+\Pi_{3} \mathrm{X} 3+---+\Pi_{\mathrm{n}} \mathrm{Xn} \ldots \ldots \ldots \ldots \ldots \ldots \ldots \ldots \ldots \ldots \ldots \ldots . . . . . . . . \ldots \ldots$

Where; $Y=$ dependent variable, $\Pi_{0}=$ intercept term, $\Pi_{1}, \Pi_{2}, \Pi_{3}$, --- $\Pi_{n}=$ regression coefficients to be determined, X1, X2, X3 ..... $\mathrm{Xn}=$ set of explanatory variables. We re-specify the model to capture the objectives of our study.

$\mathrm{GDPPC}_{\mathrm{t}}=\Pi_{0}+\Pi_{1} \mathrm{OREV}_{\mathrm{t}}+\Pi_{2} \mathrm{TGXP}_{\mathrm{t}}+\Pi_{3} \mathrm{NSAV}_{\mathrm{t}}+\varepsilon_{\mathrm{t}} ; \mathrm{t}=1,2, \ldots . \mathrm{n}$

Where; $\mathrm{GDPPC}_{\mathrm{t}}=$ Gross domestic product per capita (dependent variable), $\mathrm{OREV}_{\mathrm{t}}=$ Oil Revenue, $\mathrm{TGXP}_{\mathrm{t}}=$ Total Government Expenditure, $\mathrm{NSAV}_{\mathrm{t}}=$ National Savings and $\varepsilon_{\mathrm{t}}=$ Error term.

Where; $\Pi_{0}, \Pi_{1}, \Pi_{2}$ and $\Pi_{3}$ denote respectively the unknown intercept and slope parameters to be estimated and $\varepsilon_{\mathrm{t}}$ is the disturbance term assumed to be purely random. The vector autoregressive (VAR) model is a flexible model for the analysis of multivariate time series and it is particularly useful for describing the dynamic behaviour of macroeconomic time series (Juselius, 2006). Because of these characteristics, the VAR and the vector error correction model (VECM) approaches have been widely used in the literature.

\subsubsection{Model Specification}

GDPPC $=\mathrm{F}(\mathrm{OREV}, \mathrm{TGEXP}, \mathrm{NSAV})$

$\log (G D P C)_{t}=c_{1}+\sum_{l=1}^{p} \pi_{11}^{i} \log (G D P P)_{t-i}+\sum_{j=1}^{p} \pi_{12}^{j} \log (O R E V)_{t-j}+\sum_{k=1}^{p} \pi_{13}^{k} \log (T C E X)_{t-k}+\sum_{l=1}^{p} \pi_{14}^{k} \log (G S A V)_{t-l}+\varepsilon_{1 t}$

$\log (O R E V)_{t}=c_{1}+\sum_{i=1}^{p} \tau_{21}^{i} \log (\text { ODPC })_{t-i}+\sum_{j=1}^{p} \pi_{22}^{j} \log (O R E V)_{t-j}+\sum_{k=1}^{p} \pi_{23}^{k} \log (T C E X)_{t-k}+\sum_{l=1}^{p} \pi_{24}^{k} \log (G S A V)_{t-1}+\varepsilon_{2 t}$

$\log (T C E X)_{t}=c_{1}+\sum_{l=1}^{p} \pi_{31}^{i} \log (\text { CDPC })_{t-i}+\sum_{j=1}^{p} \pi_{32}^{j} \log (\text { OREV })_{t-j}+\sum_{k=1}^{p} \pi_{33}^{k} \log (T C E X)_{t-k}+\sum_{l=1}^{p} \pi_{34}^{k} \log (G S A V)_{t-l}+\varepsilon_{3 t}$

$\log (G S A V)_{t}=c_{1}+\sum_{t=1}^{p} \pi_{41}^{i} L o g(G D P C)_{t-i}+\sum_{j=1}^{p} \pi_{42}^{j} L \log (O R E V)_{t-j}+\sum_{k=1}^{p} \pi_{43}^{k} \log (T C E X)_{t-k}+\sum_{l=1}^{p} \pi_{41}^{k} L o g(G S A V)_{t-l}+\varepsilon_{3 t}$

\section{Result and Analysis}

We discuss the findings of empirical study conducted to examine the relationship between oil revenue (OILREV) and gross domestic product per capita (GDPPC) growth in Nigeria covering the periods 1970 to 2015. The preliminary data analysis is conducted by displaying the summary statistics of the series involved as well as the corresponding VAR extension applied based on the results from co-integrating relationship and the order of integration of the series in the models. The results for each model were presented and interpreted under the following headings:

- $\quad$ Pre-estimation, tests (unit root, cointegration, lag selection criteria test)

- Model Estimation (VECM, Granger Causality, Impulse Response Function, and Forecast Error Variance Decomposition)

- $\quad$ Post Estimation Test (Serial Correlation Test and Heteroscedasticity Test)

\subsection{Pre-estimation Tests}

\subsubsection{Unit Root Tests}

The result presented in Panel A of table 1 below shows that the majority of the time series in their log form exhibited random walk and drift properties. Only total government expenditure exhibited only the random walk property. The preceding statistical evidence formed the basis for the stationarity test conducted and results also presented in Panel B of table 1. The unit root results show that all the time series were not stationary at levels but became stationary after first difference. The time series are integrated of the same order (i.e. order 1). This shows that the 'most desirable' case (as posited by Asteriou and Hall, 2007) is evident here and hence the test of cointegration is therefore necessary. Next is the test of cointegration test. 


\begin{tabular}{|c|c|c|c|}
\hline \multicolumn{4}{|c|}{ Panel A: Properties of Time Series } \\
\hline Time series & Drift & Random Walk & Decision \\
\hline Gross Domestic Product per capita & $12.32 *$ & $0.07 *$ & Random Walk and Drift \\
\hline Oil Revenue & $-0.42 *$ & $0.23 *$ & Random Walk and Drift \\
\hline National Savings & $0.95^{*}$ & $0.23 *$ & Random Walk and Drift \\
\hline Total Government Expenditure & -0.18 & $0.20 *$ & Random Walk Only \\
\hline \multicolumn{4}{|c|}{ Panel B: Stationarity Test } \\
\hline & $\begin{array}{c}\text { ADF Test Statistics } \\
\text { (Levels) }\end{array}$ & $\begin{array}{c}\text { ADF Test Statistics } \\
\text { (1st Difference) }\end{array}$ & Order of Integration \\
\hline Gross Domestic Product per capita & -0.09 & $-5.72^{*}$ & $\mathrm{I}(1)$ \\
\hline Oil Revenue & -2.12 & $-7.11 *$ & $\mathrm{I}(1)$ \\
\hline National Savings & -2.01 & $-4.76^{*}$ & $\mathrm{I}(1)$ \\
\hline Total Government Expenditure & 3.28 & $-1.80 *$ & $\mathrm{I}(1)$ \\
\hline
\end{tabular}

Table 1: Property of Time Series and ADF Unit Root Tests

Source: Author's Computation Using Eviews 9

NB: * Implies That the Statistics Is Significance 5\%

\subsubsection{Cointegration Test}

\begin{tabular}{|c|c|c|}
\hline Trace Stat. & 5\% Crit. Value & Decision \\
\hline $48.77552^{*}$ & 47.86 & Cointegrating \\
21.32069 & 29.80 & Not Cointegrating \\
8.990883 & 15.50 & Not Cointegrating \\
2.907267 & 3.84 & Not Cointegrating \\
\hline
\end{tabular}

Table 2: Julius Johansen Cointegration Test Result

Source: Author's Computation USING Eviews 9

The selected trace test for cointegration statistics presented in table 2 above shows that the hypothesis of no cointegration, $\mathrm{H}_{0}$, among the variables can be rejected in the case of one equation.

The unit root and cointegration result make the estimation of the vector error correction mechanism (VECM) model the most appropriate in this case.

\subsubsection{Lag Selection Criteria Test}

Each of the criteria as shown in table 3 below suggested lag one. The estimation of the VECM, as shown in the next section, is therefore done with one lag. We cannot but agree that prudent spending of oil revenue should be able to boost gross domestic product per capita in one year.

\begin{tabular}{|c|c|c|c|c|}
\hline \multirow{2}{*}{} & \multicolumn{4}{|c|}{ Criterion } \\
\cline { 2 - 5 } & FPE & AIC & SC & HQC \\
\hline Lag & 1 & 1 & 1 & 1 \\
\hline
\end{tabular}

Table 3: Lag Selection Criteria Result

Source: Author's Computation Using Eviews 9

- $\quad \mathrm{FPE}=$ Final prediction error

- $\quad \mathrm{AIC}=$ Akaike information criterion

- $\mathrm{SC}=\mathrm{S}$ chwartz criterion

- $\mathrm{HQC}=$ Hannam-Quinn criterion 


\subsection{Model Estimation}

\subsubsection{Vector Error Correction Mechanism (Vecm)}

\begin{tabular}{|c|c|c|c|c|}
\hline & \multicolumn{4}{|c|}{ Equations ( $\mathrm{N}=44$ after Adjustment) } \\
\hline Elements (i.e. exogenous) & $\overline{\mathrm{D}(\mathrm{Log}(\mathrm{GDPPC})})$ & $\mathrm{D}(\log ($ OILREV $))$ & $\overline{\mathrm{D}(\log (\mathrm{TGEXP}))}$ & $\mathrm{D}(\log (\mathrm{NSAV}))$ \\
\hline \multirow[t]{3}{*}{ CointEq1 } & 0.021457 & $-0.316172^{*}$ & -0.06567 & 0.058382 \\
\hline & [1.09435] & [2.90549] & [0.98263] & {$[1.51924]$} \\
\hline & 0.039528 & 1.159647 & 0.440936 & -0.05662 \\
\hline \multirow[t]{2}{*}{$\mathrm{D}(\log (\mathrm{GDPPC}(-1)))$} & {$[0.21721]$} & [1.14819] & [0.71088] & [0.15874] \\
\hline & 0.004204 & 0.151446 & $0.244053^{*}$ & 0.046402 \\
\hline \multirow[t]{2}{*}{$\mathrm{D}(\log ($ OILREV(-1)) $)$} & {$[0.13857]$} & [0.89948] & {$[2.36022]$} & [0.78042] \\
\hline & -0.00931 & -0.29857 & -0.39655 & 0.07695 \\
\hline \multirow[t]{2}{*}{$\mathrm{D}(\log (\mathrm{TGEXP}(-1)))$} & [0.18516] & {$[1.07021]$} & [2.31452] & [0.78107] \\
\hline & -0.08138 & 0.142663 & 0.571069 & 0.074087 \\
\hline $\mathrm{D}(\log (\mathrm{NSAV}(-1)))$ & [0.86857] & [0.27435] & [1.78820] & [0.40345] \\
\hline \multirow[t]{2}{*}{$\mathrm{C}$} & 0.027645 & 0.177663 & 0.068808 & 0.191334 \\
\hline & [1.14748] & {$[1.32872]$} & {$[0.83793]$} & [4.05213] \\
\hline R-squared & 0.07166 & 0.216114 & 0.212489 & 0.187692 \\
\hline F-statistics & 0.586653 & 2.095287 & 2.050661 & 1.756053 \\
\hline
\end{tabular}

Table4: Estimated VECM Results

Source: Author's Computation Using Eviews 9

NB: T-Statistics in Parentheses [...] Are Absolute Values

* Signifies Significance at 5\%

Based on the result presented in table 4, the following analysis is made:

- A significant yearly adjustment of gross domestic product per capita from the deviation of its cointegrating values was not evident between 1970 and 2015. Hence, if a long-run relationship is broken, gross domestic product per capita will not react against the error with adjusting. But the reverse is the case with oil revenue only.

- Oil revenue had a positive and significant coefficient (i.e. 0.24) in the estimated government total expenditure equation (since the t-statistics are greater than 2.00). Thus, one period lag of oil revenue had a significant impact on government total expenditure during a current year between 1970 and 2015.

- Government total expenditure had a negative and insignificant coefficient (-0.01) in the estimated gross domestic product per capita equation (since the t-statistics of 0.19 is less than 2.00). Thus, one period lag of government total expenditure had no significant impact on gross domestic product per capita during a current year between 1970 and 2015.

- Oil revenue and government total expenditure combined weakly ( since $\mathrm{R}^{2}=0.07$ ) and insignificantly (since F-stat. of 0.59 is less than the F-crit. of 4.00) to predict gross domestic product per capita.

- Though oil revenue had a positive and significant impact on government spending, government total expenditure had no positive and significant impact on gross domestic product per capita between 1970 and 2015.

\subsubsection{Granger Causality}

\begin{tabular}{|c|c|c|c|c|c|}
\hline \multicolumn{7}{|c|}{ chi2 Statistics (p-values) } \\
\hline Dependent Variables & Log(GDPPC) & Log(OILREV) & Log(TGEXP) & Log(NSAV) & Joint Causality \\
\hline \multirow{2}{*}{ Log(GDPPC) } & & 0.019203 & 0.034285 & 0.754405 & 1.100044 \\
\cline { 2 - 6 } & - & -0.8898 & -0.8531 & -0.3851 & -0.7771 \\
\hline \multirow{2}{*}{ Log(OILREV) } & 1.318329 & & 1.145354 & 0.075268 & 2.290655 \\
\cline { 2 - 6 } & -0.2509 & - & -0.2845 & -0.7838 & -0.5143 \\
\hline \multirow{2}{*}{ Log(TGEXP) } & 0.505349 & 5.570646 & & 3.197653 & 8.313594 \\
\cline { 2 - 6 } & -0.4772 & -0.0183 & - & -0.0737 & -0.04 \\
\hline \multirow{2}{*}{ Log(NSAV) } & 0.025197 & 0.60905 & 0.610072 & & 2.020065 \\
\cline { 2 - 6 } & -0.8739 & -0.4351 & -0.4348 & - & -0.5683 \\
\hline
\end{tabular}

Table 5: Granger Causality Results

Source: Author's Computation Using Eviews 9 P-Values in Parentheses

* Implies Significance at 5\% 
Based on the result presented in table 5, the following analysis is made:

- Oil revenue significantly granger caused government total expenditure [since the p-value of the chi2 statistics is less than 0.05 (i.e. of $0.02<0.05$ ) in the government total expenditure equation].

- Government total expenditure did not significantly granger caused gross domestic product per capita [since the pvalue of the chi2 statistics is greater than 0.05 (i.e. of $0.85>0.05$ ) in the gross domestic product per capita].

- Though oil revenue granger caused government total expenditure, government total expenditure did not granger cause gross domestic product per capita between 1970 and 2015.

The analysis in sections 4.2.1 and 4.2.2 shows that oil revenue significantly accounted for government expenditure, but government total expenditure did not significantly account for gross domestic product per capita. This implies that a dynamic linkage relationship between oil revenue, government total expenditure and gross domestic product per capita was not evident in Nigeria between 1970 and 2015.

\subsubsection{Impulse Response Function (IRF)}

Based on figure 1, the following forecast can be made:

- A unit positive standard deviation shock to oil revenue will lead to a positive response from gross domestic product per capita. The effect oil revenue on gross domestic product per capita will be positive from the first year till the tenth year.

- A unit standard deviation shock to government total expenditure will lead to a negative response from gross domestic product per capita. The effect of government total expenditure on gross domestic product per capita will be negative from the first year till the tenth year.

- $\quad$ Should the past trend in government management of oil revenue continue, it's expected that gross domestic product per capita will continue to respond negatively. The General level of welfare will continue to fall as more people will become poorer.

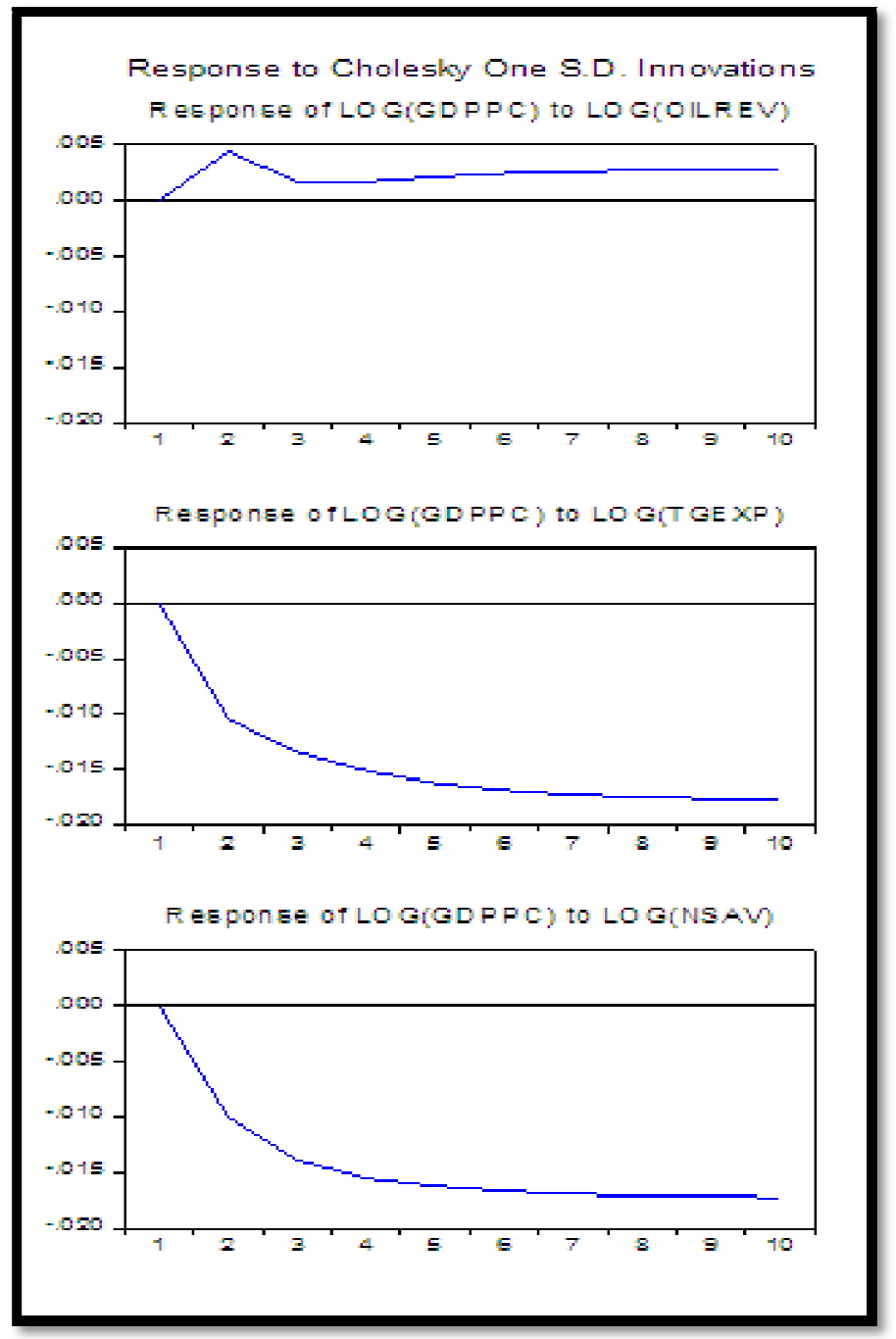

Figure 1: IRF Graphs Showing Response of GDPPC to Shock in the Explanatory Variables 
4.2.4. Forecast Error Variance Decomposition (FEVD)

Based on the result presented in table 6 , the following forecast can be made:

- Oil revenue will account for an average of $28.80 \%$ variation in government total expenditure during a 10 -year period.

- Government total expenditure will account for an average of $2.06 \%$ variation in gross domestic product per capita during a 10-year period.

- While the magnitude of percentage average variation in government total expenditure that oil revenue is expected to account for during a ten-year period is as high as 28.80; the magnitude of percentage average variation in gross domestic product per capita that government total expenditure is expected to account for during a ten-year period is as low as $2.06 \%$.

\begin{tabular}{|c|c|c|c|c|c|c|c|c|c|}
\hline & \multicolumn{3}{|c|}{ Variance Decomposition of } & \multicolumn{2}{c|}{ Variance Decomposition of TGEX } & \multicolumn{3}{c|}{$\begin{array}{c}\text { Variance Decomposition of } \\
\text { NSAV }\end{array}$} \\
\hline Period & OILREV & TGEXP & NSAV & OILREV & GDPPC & NSAV & GDPPC & OILREV & TGEXP \\
\hline 1. & 0.0000 & 0.0000 & 0.0000 & 20.97384 & 0.780831 & 0 & 0.058387 & 31.96584 & 0.136969 \\
2. & 0.1710 & 0.9351 & 0.8593 & 33.89406 & 3.574557 & 3.828244 & 1.440966 & 46.93708 & 0.049239 \\
3. & 0.1198 & 1.5195 & 1.5311 & 33.16018 & 3.490441 & 4.085412 & 3.151575 & 50.9461 & 0.182325 \\
4. & 0.0962 & 1.9367 & 1.9927 & 32.41578 & 3.158912 & 4.76565 & 4.158704 & 52.74979 & 0.259017 \\
5. & 0.0875 & 2.2539 & 2.2969 & 31.32336 & 2.774343 & 5.185285 & 4.796712 & 53.73384 & 0.335576 \\
6. & 0.0851 & 2.4938 & 2.5134 & 30.48997 & 2.468874 & 5.568437 & 5.229638 & 54.3856 & 0.391112 \\
7. & 0.0852 & 2.6790 & 2.6733 & 29.79635 & 2.226633 & 5.859702 & 5.546476 & 54.84609 & 0.436606 \\
8. & 0.0860 & 2.8235 & 2.7958 & 29.24588 & 2.036428 & 6.096109 & 5.788128 & 55.19049 & 0.472561 \\
9. & 0.0869 & 2.9382 & 2.8918 & 28.79764 & 1.884312 & 6.284889 & 5.977915 & 55.45634 & 0.501784 \\
10 & 0.0879 & 3.0307 & 2.9686 & 28.43148 & 1.761017 & 6.439245 & 6.130255 & 55.66761 & 0.525627 \\
\hline Av. & 0.0905 & 2.0610 & 2.0523 & 29.8529 & 2.4156 & 4.8113 & 4.2279 & 51.1879 & 0.3291 \\
\hline
\end{tabular}

Table 6: Forecast Error Variance Decomposition

Source: Author's Computation Using Eviews 9

From the analysis in sections 4.2.3 and 4.2.4, we can therefore forecast that a positive unit shock in oil revenue will account for a significant variation in government total expenditure; but a positive shock in government total expenditure will not account for a significant variation in gross domestic product per capita.

\subsection{Post Estimation Tests}

\subsubsection{Serial Correlation Test}

The LM test of autocorrelation result presented in table 7 shows that we cannot reject the null hypothesis of no serial correlation in the residuals at all levels of significance and all the two-lag orders. Hence, the residuals are not serially correlated.

\begin{tabular}{|c|c|c|}
\hline Lags & LM-Stat & Prob>chi2 \\
\hline 1 & 13.33 & 0.65 \\
2 & 17.35 & 0.36 \\
\hline
\end{tabular}

Table 7: VEC Residual Serial Correlation Lm Test

Source: Author's Computation Using Eviews 9

H0: No Serial Correlation at Lag Order H

\subsubsection{Heteroscedasticity Test}

\begin{tabular}{|c|c|c|}
\hline \multicolumn{3}{|c|}{ Joint Test } \\
\hline Chi-square & $\mathrm{df}$ & Prob. \\
\hline 200.79 & 200 & 0.47 \\
\hline
\end{tabular}

Table 8: Residual Heteroscedasticity Test

Source: Author's Computation Using Eviews 9

The null cannot be rejected since the p-value of the joint test is greater than 0.05 . Hence, the specified model did not suffer from heteroscedasticity problem. The model satisfied the homoscedasticity assumption. Hence the estimates passed this test too. 


\section{Summary, Conclusion and Recommendation}

This paper investigated the existence of an expected relationship between oil revenue, government total expenditure and gross domestic product per capita. The estimated VECM model showed that one period lag of oil revenue had a positive and significant impact on government total expenditure; but government total expenditure had a negative and insignificant impact on gross domestic product per capita. The impulse response function analysis also shows that though a unit standard deviation shock to oil revenue is expected to have a positive impact on gross domestic product per capita; a unit standard deviation shock to government total expenditure is expected to have a negative impact on gross domestic product per capita from the first year till the tenth year. Moreover, the analysis of the forecast error variance decomposition result shows that the magnitude of the average percentage (i.e. 29.80) variation in government total expenditure that oil revenue is expected to account for during a ten-year period is very high when compared with the magnitude of the average percentage (i.e. 2.06) variation in gross domestic product per capita that oil government total expenditure is expected account for during a ten-year period. This study concludes that while government expenditure so far has been reliant on oil revenue, the pattern of government expenditure has not impacted positively on GDP per capita. Government spending of oil revenue has not led to improvement in the general income level of the people of Nigeria. The study, therefore suggests efficient and transparent spending of oil revenue to improve the general well-being of Nigerians.

\section{References}

i. Awe, A., A and Ajayi, S., O (2009). Diversification of Nigerian Revenue Base for Economic Development: The Contribution of the Non-Oil Sector. Pakistan Journal of Social Sciences, 6: 138-143.

ii. Akanni, O.P. (2007). Oil wealth and economic growth in oil exporting African countries, AERC research paper 170, Nairobi: AERC.

iii. Bakare, A., S. and Fawehinmi, F., O. (2011).An econometric study of the contribution of oil

iv. Sector to the standard of living in Nigeria (1975-2008). Asian Journal of Business and

v. Management Sciences, 1(3), 1-8.ISSN 2047-252

vi. CBN (1974). Origin and Development of Inflationary Trend in African Countries (Impact on Their Growth). CBN Economic and Financial Review, Vol. 12 No 2 December

vii. CBN (1996). Money Supply, Inflation and the Nigerian Economy Bullion Publication of CBN, Vol. 21 No 3 July/ September.

viii. CBN (2015). CBN Statistical Bulleting. Vol. 14 December.

ix. CBN (2017). Central Bank of Nigeria Quarterly Statistical Bulletin Vol 6, No 4, December 2017 Statistical

x. Chidinma, L. U (2010). The relative impact of oil and non-oil exports on economic growth in Nigeria: 1983 to 2007. https:/ / www.scribd.com/ document/ 240298513/ ec6 2010

xi. Chinyere, C., G (2012) Empirical investigation on the impact of export trading on economic growth in Nigeria. www.unn.edu.ng/ .../ CHUKWU\%20GRACE\%20CHINYERE\%20-\%20Main\%20Work

xii. CIA (2018). The World Fact book, Country Profiles, Central Intelligence Agency. 2018

xiii. EIA (2016). EIA - Annual Energy Outlook 2016. https:/ / www.eia.gov/ outlooks/ aeo/

xiv. Grossman, G. and E. Helpman (1994). Endogenous Innovation in the Theory of Growth. Journal of Economic Perspectives 8 (1)

xv. IMF (2018). World Economic Outlook Database. GDP based on Purchasing Power Parity. International Monetary Fund. 2018

xvi. Kalbasi, N (2010). Economic growth convergence among Middle. Journal of Economics and International Finance Vol. 2(10), pp. 231-236, October 2010. http://www.academicjournals.org/JEIF ISSN 2006-9812 @2010 Academic Journals

xvii. Kui-Wai, L and Xianbo, Z (2011). Cross-country Convergence and Growth: Evidence from Nonparametric and Semiparametric Analysis. APEC Study Center Consortium Conference

xviii. September 22 - 23, 2011, San Francisco, USA

xix. Lucas, R., E (1988). On the Mechanics of Economic Development. Journal of Monetary Economics. 22 (1): 3-42. Doi: 10.1016/ 0304-3932(88)90168-7.

xx. Roemer, M. and Gugerty, M.K. (1997). Does Economic Growth Reduce Poverty? Harvard Institute for International Development; Technical Paper.

xxi. Sachs, Jeffrey, (1996). Growth in Africa: It can be done. The Economist, June 29: 19-21.

xxii. Sachs, Jeffrey and Andrew Warner, (1995a). Economic Convergence and Economic Policies. Harvard Institute for International Development, Development Discussion Paper 502.

xxiii. Sachs, Jeffrey and Andrew Warner, (1995b). Natural Resource Abundance and Economic Growth. Harvard Institute for International Development, Development Discussion Paper 517a.

xxiv. Solow, R (1957).Technical change and the aggregate production function, Review of Economic Studies, vol. 39, pp. 312-330, 1957.

xxv. Schumpeter, J. A. (1934). The Theory of Economic Development. Oxford, Oxford University Press.

xxvi. Solow, R.M. (1956). A Contribution to the Theory of Economic Growth. The Quarterly Journal of Economics, Vol. 70, No. 1. (Feb., 1956), 65-94. 
xxvii. Smith, A (1776). An Inquiry into the Nature and Causes of the Wealth of Nations. 1 (1 Ed.). London: W. Strahan. Retrieved 2012-12-07, volume 2 via Google Books

xxviii. Romer, Paul M., (1986). Increasing returns and long-run growth, Journal of Political Economy 94, 1002-1037

xxix. Swan, T., W (1956). Economic growth and capital accumulation, The Economic Record, 1956, vol. 32, issue 2, 334-361

xxx. World Bank (2016) Annual Report www.worldbank.org/ en/ about/ annual-report-2015/ annual-report 